Relationship-based early childhood intervention services for children with complex

needs: The case for effective cross -sector working in Newham through the development of an Integrated Early Intervention Model for Children with Speech Language and Communication Needs (SLCN)/ Autistic Spectrum Condition (ASC) in PVI Settings

Alison Lentz, Kari Askey and Eunice Costello, Newham SEND Hub, Anne Thorne, Longcause Community Special School and Carolyn Blackburn, Birmingham City University.

This document is the Accepted Manuscript version of a Published Work that appeared in final form in EYE, copyright (C) MA Education, after peer review and technical editing by the publisher. To access the final edited and published work see http://www.magonlinelibrary.com/toc/eyed/current

\title{
Introduction
}

This article discusses a reflective account from members of staff from the Newham SEND Hub from their visit to Longcause Community Special school to observe a relationship-based early childhood intervention service for children diagnosed with autistic spectrum disorder (ASD).

Early Childhood Intervention (ECI) focuses on children's early development and acknowledges the ever widening population of very young vulnerable children. ECI specifically focuses on vulnerable children from conception until the age of six years. Infancy is a crucial developmental stage when an individual forms the core of his/her conscience, tests his/her confidence with his/her body, establishes intensive interpersonal bonds, develops the ability to trust and relate to others, and lays down the foundation for lifelong learning and thinking. The aim of ECI services is to support families and significant caregivers as mediators for their child's acquisition of competences within natural environments, enabling children and their families to meaningfully participate and support their development during their daily routines. In this way, children can maximise their development, achieve their potential and also build strong and enduring relationships with key people in their lives. In this regard, ECI services must operate from the perspective that each child, no matter what developmental challenges faced, will learn and grow through relationships with his or her family and significant caregivers, supported by and in partnership with highly trained skilled professionals under a family-centred approach. These dimensions have been shown to be instrumental in the delivery of centre-based ECI services delivered at the Champion Centre in New Zealand http://www.championcentre.org.nz/ and to result in positive developmental outcomes for children and a range of wellbeing outcomes for families (Blackburn, 2015, 2016a, 2016c; Foster-Cohen, 2005; Foster-Cohen \& van Bysterveldt,, 2016a, 2016b; Worthington, 2016). Newham are currently exploring relational approaches to establishing effective cross-sector working.

\section{Relationship-based approach}

Longcause is a community special school for children with ASC (4-16yrs). Newham's visit to Longcause was arranged so they could see the only UK replication of the Champion Centre model to early, intensive support to children with high level special educational needs and disabilities (SEND) and their families. We spent an inspiring day, welcomed by head teacher Anne Thorne and her colleagues, experiencing the 'carousel' system first hand and meeting the parents and children being supported so successfully through this project. 
The target group for the intervention at Longcause is a group of six children who had started in reception in September 2016 and whose parents were open to the intervention. Parents attend a block of eight Wednesday morning sessions during the Spring Term accessing a 'carousel' system with their children. After a short break there is a second block of five weeks in the Summer Term. The 'carousel' comprises six groups:

- Early Communication run by a teacher

- Attention Autism run by a teaching assistant

- Musical Play run by a music therapist

- Occupational Therapy

- Playworx run by a teaching assistant

- Family Support run by the FSW

Each family is given a photo board with the six photos of the key staff arranged in the order of their 20 minute group sessions. They collect their child from class and rotate around the six groups independently. For our visit we were each attached to a family giving us the opportunity to see the impact, six weeks into the programme, of this work on the whole family.

Vignette: A is 5 years old and before Longcause attended a local nursery. Mum felt the local nursery never really 'got him'. She is really happy with the progress he has made since starting school and really appreciates this programme because it has given her new ideas of managing his behaviour effectively. After meeting A in his classroom we begin the carousel:

\section{Playworx}

The family are welcome into the room and mum immediately demonstrates how much she has learnt from these sessions by producing a bubble blower she has purchased: she understands the importance of developing A's oral skills and knows this particular toy produces many bubbles for one puff and A clearly enjoys it! The Play Worker congratulates Mum on her initiative and it is really positive to see Mum in control of this part of the session. From a limited choice A is able to select activities and the Play Worker ensures that Mum is involved at all stages. Mum is able to report on progress she has made with A at home and how the skills are transferrable. The Play Worker explains there are four aspects to Theraplay (the model in use): nurture (positive touch); challenge (tiny next steps); structure (ready, steady, go) and engagement.

\section{Attention Autism}

The family move to another room where the TA and her 'attention bucket' await. The TA begins by planning the session on the whiteboard using picture clues and words. The structure of the session means both A and his mum can anticipate what is coming next. A is totally engaged by the white board and is able to work through the short list of activities with confidence. The TA engages mum in all the turn taking aspects, letting her take the lead, then altering the order of participation. Sometimes A needs time to adjust to this but the TA is adept at re-engaging him. She also understands what could be a block for him (pancake activity) and gives him ample warning and accommodation (you don't have to eat it). The TA really appreciates this individual attention to detail as it clearly leads to a successful session. 


\section{Music Play}

Before we enter the music studio mum confides this is the session she finds the most challenging. A immediately switches off the lights, has fleeting interest in the instruments and wants to run around. Both the music therapist (playing calming tunes on the piano) and Mum (singing favourite rhymes and songs) find it difficult to engage with him. But both are committed to keep on trying.

\section{Family Support}

After a coffee break, when A is returned to his friends in class, it is time for Mum to meet with the Family Support Worker. Mum proudly explains a resolution she has made regarding social media and the FSW commends her bravery in addressing what has been an increasingly frustrating problem for her. Mum can report an immediate positive outcome of her decision on the quality of family life. Mum's understanding of A's condition and her ability to self-reflect are noticeable..

\section{Occupational Therapy}

As we meet the OT in the specialist OT room A displays great familiarity by removing his shoes and diving into the ball pool. A is sufficiently relaxed and trusting of the OT that he readily engages in rough and tumble play. The OT does a lot of reflex vibration work so that A can 'feel' the difference in the chest between ' $a$ ' and 'e'. He identifies that A has difficulty with closed lip sounds and A allows the OT to gently hold his lips together whilst making 'mmmmm' sound. Later in the session A is really concentrating in his attempt and successfully producing this sound independently. This is celebrated by all the adults! The OT provides a full commentary of the interventions he is using, in technical language and jargon free. It is a really helpful way to explain his reasoning to Mum and she can see the positive outcomes for $\mathrm{A}$ and be inspired to continue this at home.

\section{Early Communication}

This is organised in the library and A settles immediately he sees the PECS board. He attempts to voice out the sentence and is clearly familiar with the coloured eggs it refers to. The first is the green egg which he retrieves easily. Fran reads the message inside and provides the corresponding activity. A is able to change the colour words in the PECS sentence and select different eggs accordingly. The reward is the activity and he is able to choose who does this - at one point it is me, a relative stranger, indicating that he is beginning to widen his social circle. Towards the end of the session, the teacher and mum use 'under the blanket' activity. Mum explains that A had real problems with this to begin with but was now tolerating it.

\section{Reflection}

At the end of the morning the children are returned to class. It is an opportunity for us to talk with the parents. It is clear that although each group has a consistent ethos and aim the elements are tailored to the need of each child individually. The programme respects the whole child and the family context as unique and all the parents are all highly positive about 
it. However, they talk about their previous experiences with sadness and regret. They have had a range of different early experiences including late diagnosis, insufficient early support, social isolation and lack of clarity about future plans for their children. Overwhelmingly, they are all pleased to have found their way to Longcause. Whilst it is clear the parents acknowledge that much progress is down to the dedication of the school staff they all see the advantages of working together with the therapists and their children, feel they have learned new methods, are pleased that their opinions count for something, and are confident that they are not alone.

After the parents leave and staff have attended to the lunch break the professionals meet to discuss the morning. This is a relaxed information-sharing session where each child is discussed individually by all the team. It is clear to see that, whilst each group runs on similar lines with the same equipment, the acceleration of progress is highly individualised and the focus is as much on the parent as the child. The handing over of the 'reins' to the parent is key. Indeed, of the six groups I attended I witnessed mum moving from a position of shared leadership in most to a much more obvious leadership in one. Her confidence was palpable and she explained the reasoning as well as any professional. Moving parents into this position is powerful on many levels:

- It truly acknowledges the role of the parent as the first educator rather than just paying lip service to a well-worn phrase;

- parents are acknowledged as experts on their own child and can share their wellinformed opinions with professionals which can save time;

- working together parents and professionals can piece together a more holistic picture understanding the child in the context of their home life as well as their school life;

- therapy practices become ingrained in daily life thus maximising the impact of expensive therapy time;

- parents become advocates for their child as they make sense of the world and this could reduce the likely involvement of social care as children get older and life becomes harder to navigate sensibly.

\section{Summary and conclusion}

It was a genuine privilege to see the 'carousel' in action at Longcause. It is clear that this method of working, bringing therapists and aspects of therapy (as delivered by trained professionals) together in one place provides a cohesive message of support to parents at a most vulnerable time in their lives. Like most parents of children with SEND these felt the system had not always supported them but felt this programme was beginning to address this.

In Newham children with SEND who are not yet in the school system, at home, in a private nursery, voluntary playgroup or with a child-minder, can be further disadvantaged by an inconsistent access to support services.

Susan Foster-Cohen, Director of the Champion Centre will be speaking at a conference in Birmingham in July 2017 about the Champion Centre model and their program for children born prematurely https://www.eventbrite.co.uk/e/interdisciplinary-perspectives-onpremature-birth-conference-tickets-33332879540 


\section{References:}

Blackburn, Carolyn. (2015). Relationship-based early intervention services for children with complex needs: Lessons from New Zealand. Report to the Winston Churchill Memorial Trust. Birmingham, UK: Birmingham City University.

Blackburn, Carolyn. (2016a). Relationship-based early intervention services for children with complex disabilities. Journal of Children's Services, 11(4), 330-344.

Blackburn, Carolyn. (2016b). Relationship-based early intervention services for children with complex needs: lessons from New Zealand. International Journal of Birth and Parent Education, 3, 27-30.

Foster-Cohen, S. H. (2005). Beyond the Difference: The Champion Centre.

Foster-Cohen, S. H., \& van Bysterveldt, A. K. (2016a). Assessing the communication development of children with language delay through parent multi-questionnaire reporting. Speech, Language and Hearing, 1-8.

Foster-Cohen, S. H., \& van Bysterveldt, A. K. (2016b). Early Childhood Inclusion in Aotearoa New Zealand. Infants \& Young Children, 29(3), 214-222.

Worthington, Lynne. (2016). Investigating the Value of the Early Intervention Programme: A Programme Differentiation Analysis. Christchurch, New Zealand: Research First. 